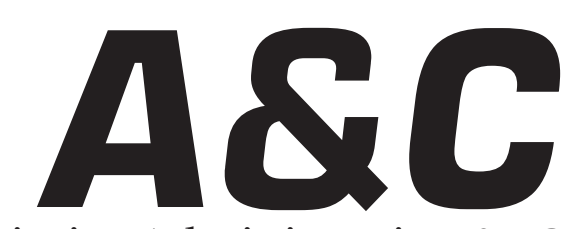

Revista de Direito Administrativo \& Constitucional

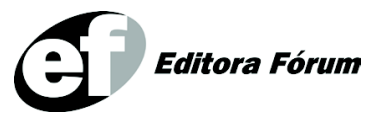

ISSN $1516-3210$ 


\section{A\&C REVISTA DE DIREITO ADMINISTRATIVO E CONSTITUCIONAL}

IPDA

Instituto Paranaense

de Direito Administrativo

Direção Geral

Romeu Felipe Bacellar Filho

Direção Editorial

Paulo Roberto Ferreira Motta

Direção Executiva

Emerson Gabardo

Conselho de Redação

Edgar Chiuratto Guimarães

Adriana da Costa Ricardo Schier

Célio Heitor Guimarães

\section{Conselho Editorial}

Adilson Abreu Dallari

Alice Gonzáles Borges

Carlos Ari Sundfeld

Carlos Ayres Britto

Carlos Delpiazzo

Cármen Lúcia Antunes Rocha

Celso Antônio Bandeira de Mello

Clèmerson Merlin Clève

Clóvis Beznos

Enrique Silva Cimma

Eros Roberto Grau

Fabrício Motta

Guilhermo Andrés Muñoz (in memoriam)

Jaime Rodríguez-Arana Muñoz

Jorge Luís Salomoni

José Carlos Abraão
José Eduardo Martins Cardoso
José Luís Said
José Mario Serrate Paz
Juan Pablo Cajarville Peruffo
Juarez Freitas
Julio Rodolfo Comadira
Luís Enrique Chase Plate
Lúcia Valle Figueiredo
Manoel de Oliveira Franco Sobrinho
(in memoriam)
Marçal Justen Filho
Marcelo Figueiredo
Márcio Cammarosano
Maria Cristina Cesar de Oliveira

Nelson Figueiredo

Odilon Borges Junior

Pascual Caiella

Paulo Eduardo Garrido Modesto

Paulo Henrique Blasi

Paulo Neves de Carvalho (in memoriam)

Paulo Ricardo Schier

Pedro Paulo de Almeida Dutra

Regina Maria Macedo Nery Ferrari

Rogério Gesta Leal

Rolando Pantoja Bauzá

Sérgio Ferraz

Valmir Pontes Filho

Yara Stropa

Weida Zancaner

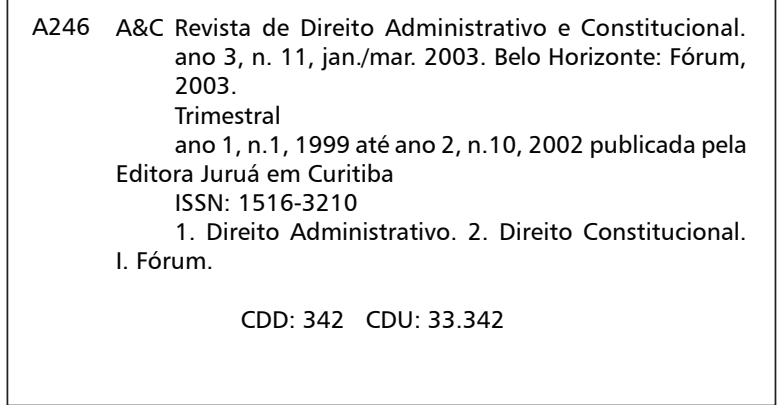

(c) Editora Fórum Ltda. 2006

Todos os direitos reservados. É proibida a reprodução total ou parcial, de qualquer forma ou por qualquer meio eletrônico ou mecânico, inclusive através de processos xerográficos, de fotocópias ou de gravação, sem permissão por escrito do possuidor dos direitos de cópias (Lei $n^{\circ}$ 9.610, de 19.02.1998).

\section{Editora Fórum Ltda}

Av. Afonso Pena, 2770 - 15\%16ªndar - Funcionários

CEP 30130-007 - Belo Horizonte/MG - Brasil

Tel.: 08007043737

Internet: www.editoraforum.com.br

e-mail: editoraforum@editoraforum.com.br
Editor responsável: Luís Cláudio Rodrigues Ferreira Projeto gráfico e diagramação: Luis Alberto Pimenta Revisora: Olga M. A. Sousa

Pesquisa jurídica: Fátima Ribeiro - OAB/MG 74868

Bibliotecária: Alessandra Rodrigues da Silva CRB 2778/MG 6 ${ }^{\text {a Região }}$

Os conceitos e opiniões expressas nos trabalhos assinados são de responsabilidade exclusiva de seus autores.

Impressa no Brasil / Printed in Brazil

Distribuída em todo Território Nacional 


\title{
Segurança jurídica: fundamento do Estado de Direito
}

\author{
Lígia Maria Silva de Melo \\ Advogada. Professora de Direito Administrativo da UnicenP e do Instituto de Direito Romeu \\ Felipe Bacellar
}

Sumário: 1 Introdução - 2 A formação do Estado: fundamento na segurança 3 Estado de Direito e a segurança jurídica - 4 A dignidade da pessoa humana e a segurança jurídica - 5 Conclusão - Referências

Palavras-chave: Segurança jurídica. Estado Democrático de Direito. Princípio da dignidade da pessoa humana. Estado. Relações sociais.

\author{
Se a insegurança nos incomoda, a possibilidade de trabalhar \\ pela segurança nos conforta. *
}

\section{Introdução}

Em tempos em que, praticamente, não há mais fronteiras entre os países, fruto da globalização econômica, política e cultural, assistimos inertes às transformações do conceito de Estado e à disseminação de novas tecnologias de informação que acabam por repercutir e conduzir a vida dos indivíduos. Por conseguinte, como um fenômeno que surge com um novo tempo, vemos crescer, a cada instante, a sensação de insegurança e os riscos de frustrar todas as expectativas para a construção de um futuro melhor, seja no plano individual ou no coletivo.

A segurança é, sobretudo, uma necessidade antropológica do homem para que possa conduzir de forma autônoma e responsável sua vida, buscando, com grau mínimo de previsibilidade, saber no que confiar e, por conseguinte, amenizar suas inquietudes, oriundas da constante incerteza nas relações sociais. Essa necessidade de segurança tem raízes instintivas, sendo elemento precedente na formação e organização social, para que lhe seja possível uma existência pacífica, com os seus semelhantes ou consigo mesmo.

A segurança jurídica, portanto, convém às normas jurídicas, tanto quanto à conduta humana. Como um dos fundamentos do Estado de Direito, a segurança jurídica garante a grande aspiração de estabilidade buscada pela sociedade. A justiça, ideal buscado pelo direito, e o bem-estar * Cármen Lúcia Antunes Rocha.

A \& C R. de Dir. Administrativo e Constitucional, Belo Horizonte, ano 6, n. 25, p. 133-144, jul./set. 2006 
social, conseqüência do respeito a esse ideal, não se configuram sem a presença de um mínimo de segurança.

Apresenta-se como um princípio geral do Direito, refletindo em todas as áreas que o direito baliza, traduzindo o mínimo de certeza positivada em um ordenamento. É impossível ao homem conviver com o semelhante à sombra de todas as dúvidas e incertezas que permeiam sua existência. Ao menos naquilo que advém do sistema, da ordem jurídica instituída, que tenha, ele, a possibilidade do mínimo de previsibilidade.

\section{A formação do Estado: fundamento na segurança}

A luta pela satisfação da necessidade de segurança tem se demonstrado um dos principais motores da história jurídica. $\mathrm{O}$ fenômeno do surgimento do Estado e da institucionalização do Direito revelou-se, desde a Antigüidade, como conquistas dos povos na busca pela limitação dos poderes e das conseqüentes arbitrariedades no seu exercício.

Ao se examinar as principais teorias sobre a formação do Estado, ${ }^{1}$ destaca-se em primeiro plano que, seja por formação espontânea, contratual, fundada em atos de violência e força ou em causas econômicas ou patrimoniais, o ponto comum entre elas é a necessidade de proteção. A necessidade de uma instituição que assegurasse a convivência social pacífica e regulasse as relações.

O apelo ao valor da segurança como pressuposto e função do Estado será lugar comum na tradição contratualista, ${ }^{2}$ onde parte dos seus pensadores concebia o trânsito do estado de natureza à sociedade como a superação do ius incertum e sua conversão em estado de segurança. Sem a intenção de desconsiderar os demais teóricos, ressalta-se Thomas Hobbes, descrevendo claramente em sua obra, que a busca incessante do homem pela segurança leva ao surgimento do Estado, que se firma como garantidor das leis naturais. ${ }^{3}$

Das teorias que insistem na origem econômica, a de Carl Marx e Engels também traduz de forma prática o que se defende neste trabalho, ao insistir em afirmar que o Estado é produto da sociedade para assegurar

\footnotetext{
DALLARI, 2000, p. 53.

2 BOBBIO, 2000, p. 118: "O contratualismo é a forma específica através da qual o Estado é concebido como ente artificial, produzido não a partir da natureza, mas da concordante vontade dos indivíduos".

3 O fim último, causa final e desígnio dos homens (que amam naturalmente a liberdade e o domínio sobre os outros), ao introduzir aquela restrição sobre si mesmos sob a qual os vemos viver nos Estados, é o cuidado com sua própria conservação. HOBBES, 1997, p. 141.
} 
o domínio da classe possuidora de bens sobre a não-possuidora. ${ }^{4}$

É no Estado pois, que percebemos claramente a presença necessária da positivação da segurança. As relações do Estado com os particulares revelam a estrita conexão entre o poder político e segurança, traduzida em uma convivência, nem sempre harmônica, resultado de um processo de superposição do poder institucionalizado na sociedade e a manutenção das liberdades individuais.

\section{Estado de Direito e a segurança jurídica}

Em perspectiva histórica, verifica-se que, no Estado Moderno, ao assistir a sucessão do Estado liberal, após falência da idéia de liberdade desmensurada, onde apenas se mantinha a igualdade formal entre os cidadãos, pela intervenção proposta pelo Estado Social, também há crise de estabilidade nas relações em sociedade, mesmo que este atue no intuito de manter o equilíbrio social. O crescimento da produção legislativa, seja pelo poder pertinente ou pelo Executivo exercendo função atípica, cria um desnorteamento da própria essência do Estado. A atividade legalista e formal, desconectada da juridicidade, bem defendida pela ilustre Cármen Rocha, ${ }^{5}$ gera e vem gerando grande instabilidade para a sociedade. Assistimos a um excesso de poder estatal, pautado em regime de direito.

Como princípio do Estado de Direito, a segurança jurídica garante a previsão de comportamentos que devem ser seguidos pela sociedade e que nos são caros, pois definidores do nosso futuro como indivíduos. Podemos citar as normas que regem o enlace matrimonial, as regras para sua dissolução, guarda de filhos, pensão, sucessão. No âmbito da transgressão de normas de conduta, o direito penal prevê aqueles que são crimes contra a sociedade, a forma de se julgar e condenar, garantindo a presunção de inocência. Permite a previsibilidade — tão necessária ao homem - e a objetividade na interpretação das leis, a partir dos preceitos constitucionais, que instrumentalizam a busca pelo ideal de justiça.

Nos tempos atuais, em nosso país, o postulado da segurança jurí-

\footnotetext{
4 " $[. .$.$] uma instituição que, em uma palavra, não só perpetuasse a nascente divisão da sociedade em$ classes, mas também o direito de a classe possuidora explorar a não-possuidora e o domínio da primeira sobre a segunda. Inventou-se o Estado." ENGELS, p. 102-160.

5 "No Estado Democrático de Direito a juridicidade entranha o sistema normativo constituído e praticado. Não há comportamento, menos ainda do Estado,invulnerável ao toque controlador da segurança da relação da juridicidade." ROCHA, 1994.
}

A \& C R. de Dir. Administrativo e Constitucional, Belo Horizonte, ano 6, n. 25, p. 133-144, jul./set. 2006 
dica decorre de todo o artigo $5^{\circ}$ da Constituição Federal de 1988, garantindo a todos os brasileiros e estrangeiros residentes do país, o primado da segurança, dentre outros direitos e garantias fundamentais.

Em nossa Carta Magna, a manifestação de tal princípio pode ser citada em várias passagens. Necessário ressaltar que o Princípio da Segurança Jurídica possui conexão direta com os direitos fundamentais, além de estar diretamente ligado aos princípios já citados, dando funcionalidade ao ordenamento jurídico brasileiro.

A proteção ao direito adquirido, à coisa julgada e ao ato jurídico perfeito, prevista no referido artigo, em seu inciso XXXVI, ainda, os institutos da prescrição e da decadência, o princípio da anterioridade em matéria tributária.

A expressão direito adquirido vem do latim acquisitus, do verbo acquirere, adquirir, alcançar. Direito adquirido é aquele que a lei considera, de forma definitiva, integrado ao patrimônio de seu titular. ${ }^{6}$ Assim, quando alguém, na vigência de uma lei determinada, adquire um direito relacionado a esta, sobredito direito se incorpora ao patrimônio do seu titular mesmo que este não o exerça, de tal modo que, lei nova que intente revogar uma anterior relacionada ao direito, não possa ofender o status adquirido, embora não tenha sido exercido ou utilizado.

A funcionalidade que se defende surgir com a segurança é o resultado prático da norma posta. O ordenamento jurídico foi instituído como meio idôneo para proteger as relações sociais. E, para que haja estabilidade nas situações jurídicas, as normas positivas devem existir previamente aos fatos que regulam. ${ }^{7}$ Para tanto, é necessária a fixação de limites e prazos que regularão a pessoa, natural ou jurídica, no exercício do direito que julga possuir.

É interessante cuidar em não interpretar a segurança jurídica com o entendimento de que se traduz em engessamento das relações jurídicas. Corrobora-se com o pensamento de Cármen Lúcia A. Rocha, "Mas a segurança não é imutabilidade, pois esta é a própria morte." $\mathrm{O}$ que solicita o homem, é tão somente a certeza de que o Estado de Direito lhe possibilita certezas, que a ordem jurídica estabelecida possui credibilidade, já que o Direito se justifica para dar segurança ao homem.

\footnotetext{
BARROSO, 2004

"... Lopez de Onate denomina pré-ordenamento normativo - , pois este requisito de existência é o elemento básico da previsibilidade das normas..." GARCIA NOVOA, 2004.

8 ".... A vida, esta, rege-se pelo movimento, que é próprio de tudo que vive." ROCHA, 2004b.
}

A \& C R. de Dir. Administrativo e Constitucional, Belo Horizonte, ano 6, n. 25, p. 133-144, jul./set. 2006 
Diante dessa crescente instabilidade, não só jurídica como, também, social, não poderia ser outro o princípio a ser discutido. Embora, não se negue sua importância, ainda é parco o material produzido pela doutrina.

Não somente no Brasil, mas em âmbito internacional, vemos as relações entre países cada vez mais fragilizadas. Há também uma crise da noção de território, onde o desrespeito à soberania e autonomia incentivo a guerras, invasões parecem não ser atingidos por nenhuma ordem jurídica que exija melhor conduta daqueles que detêm maior poderio econômico em detrimento dos menos abastecidos.

Há de se ressaltar que o comando desse princípio, mesmo que, aparentemente abstrato, não está voltado apenas para a regulação das condutas humanas e dos agentes públicos, mas, igualmente, para a elaboração das normas que darão a sustentação legal necessária a amparar toda e qualquer conduta que fere direito ou possa feri-lo.

É, pois, na Constituição, nosso sistema de normas fundamentais positivadas, a ser respeitada por todos que compóem o Estado, governantes e governados, que se encontra o limite principiológico a ser observado.

Os princípios informadores possibilitam que a Justiça possa se cumprir, como bem defende Cármen Rocha, ${ }^{9}$ " $[\ldots]$ segundo normas asseguradoras do modelo de vida escolhido, sem impor a petrificação de um determinado paradigma normativo, [....]".

Da Constituição retira-se a identidade de uma sociedade, pois tradutora dos anseios da mesma. Os valores eleitos formam a essência do sistema constitucional, que cuidadosamente respeitados, alcançam harmonia para imprimir justiça em cada atuação Estatal. Ao Estado, ${ }^{10}$ aquele que hoje conhecemos, no exercício de suas funções, é dada a possibilidade de tudo fazer para atender ao interesse dessa sociedade, de forma legítima e justa.

O reconhecimento, entretanto, do status jurídico do princípio da segurança jurídica, e, mais especificamente, de sua hierarquia constitucional, somente se deu após percorrer longo caminho, tendo sua eficácia sido reconhecida primeiramente no âmbito do direito privado, onde sua manifestação era, e ainda o é, adotada na seara contratual através da observância do princípio da confiança, e, principalmente, nos institutos da prescrição e da decadência. Somente depois, com o firmamento do direito administrativo, é que passa a ser inspirador, pois necessário, a

${ }^{9}$ ROCHA, 1994, p. 21

${ }^{10}$ KELSEN, 1998.

A \& C R. de Dir. Administrativo e Constitucional, Belo Horizonte, ano 6, n. 25, p. 133-144, jul./set. 2006 
busca de uma maior estabilidade dos atos administrativos expedidos pela Administração pública e que têm como mister conferir ou restringir direitos. É, ao que se parece, no âmbito do direito administrativo, pois, que, a segurança passa a ser reconhecida como verdadeiro princípio constitucional, quando cuida de tutelar a relação entre o Estado-Administração e o indivíduo, protegendo-o da ação estatal.

Daí, ressaltar a Segurança Jurídica como princípio eleito no Regime Jurídico Administrativo.

A Administração Pública tem como finalidade fazer com que os efeitos determinados pelas normas jurídicas se concretizem. Sua finalidade é, então, atender ao interesse público, mesmo que por vezes se veja personificado no interesse de uma só pessoa. Ao suprir a necessidade apresentada pela sociedade, exercitando sua função administrativa, temos a aplicação prática e diária da lei. Aqui, localiza-se a segurança como princípio componente do regime jurídico administrativo.

A Lei $n^{\circ} 9.784$ de 1999, que trata do Processo Administrativo em âmbito federal, traz em seu bojo a previsão normativa do Princípio da Segurança Jurídica para nortear a atividade exercida através da função administrativa. Cuida de determinar a atuação estatal no que se refere a decisões adotadas na aplicação de sanções administrativas ${ }^{11}$ internas e externas - penas disciplinares, multas —, onde há interferência do poder público na individualidade do servidor público ou cidadão. Tal atuação está sujeita a controle posterior pelo Judiciário, motivo pelo qual cabe ao agente a estrita observância aos vetores principiológicos, a lei declara explicitamente, sob risco de ultrapassar a fronteira entre a restrição do direito e o desrespeito ao direito do destinatário da ação.

Ao que parece, a segurança jurídica se manifesta como uma necessidade exigente de regular estrutural e funcionalmente o sistema jurídico, de tal forma que vincule normas e atuações institucionais. Tal função transmite o comando do respeito a direitos e realização da justiça na correta atuação dos órgãos encarregados de aplicação das normas. Seria assegurar o completo atendimento aos comandos normativos, mediante sujeição de todas as funções exercidas pelo Estado, e o cumprimento por todos os cidadãos. A segurança jurídica, de forma simples, está intimamente ligada aos elementos objetivos da ordem jurídica, representando a garantia de

${ }^{11}$ OLIVEIRA, 1997, p. 306, item 52.2.

A \& C R. de Dir. Administrativo e Constitucional, Belo Horizonte, ano 6, n. 25, p. 133-144, jul./set. 2006 
estabilidade jurídica, segurança de orientação e realização do direito. ${ }^{12}$

Ao observamos tais características, a segurança jurídica em seus vários aspectos, citamos o mestre Canotilho a denominar o Princípio da Segurança Jurídica:

O indivíduo tem do direito poder confiar em que aos seus actos ou às decisões públicas incidentes sobre os seus direitos, posições ou relações jurídicas alicerçados em normas jurídicas vigentes e válidas por esses actos jurídicos deixados pelas autoridades com base nessas normas se ligam os efeitos jurídicos previstos e prescritos no ordenamento jurídico. ${ }^{13}$

No Direito Administrativo, travam-se cada vez mais discussões sobre o desempenho da segurança jurídica na garantia das prerrogativas individuais. Mais especificamente, o fenômeno da inflação legislativa tem gerado profundas controvérsias no seio da comunidade jurídica, principalmente quando se procedem alterações nos regimes jurídicos de relações continuadas, como no regime estatutário dos servidores públicos ou no regime geral da previdência, atacado pelo Executivo e legitimado pelo Judiciário, ou ainda no caso da exceção parcial ao princípio da anterioridade, trazido pela Emenda $n^{\circ} 33 / 2001$, onde se permite que os convênios de ICMS reduzam e restabeleçam as alíquotas sem necessidade de observância à anterioridade no restabelecimento. Cada vez mais crescem situações, criadas maquiavelicamente no exercício abusivo da legiferância, em que o cidadão não tem o direito de invocar direito adquirido, ressaltado como garantia na Constituição Federal.

As mudanças nas regras de concessão de vantagens ou benefícios ocasionaram efetiva lesão ao princípio da segurança jurídica, frustrando expectativas legitimamente traçadas com base na legislação então vigente. Não podemos esquecer que, no advento da Emenda Constitucional $\mathrm{n}^{\circ}$ 19/98, o legislador, demonstrando sensibilidade e reconhecimento à importância da Segurança Jurídica, cria regras de transição para quem já havia adquirido direito à aposentação. Tal ato não o eximiu da responsabilidade de lesar o direito, porém, ameniza o fardo ao reconhecer a necessidade humana de um mínimo de regras que sustentem a turbulenta instabilidade gerada. Como discutir que não há direito adquirido, e portanto, segurança juridicamente amparada, diante de um direito que reflete a dignidade do trabalhador? O cidadão, ao aderir a um sistema de seguridade

12 V. CANOTILHO, 2001, p. 256.

${ }^{13}$ CANOTILHO, 2001, p. 256.

A \& C R. de Dir. Administrativo e Constitucional, Belo Horizonte, ano 6, n. 25, p. 133-144, jul./set. 2006 
— mais uma vez a segurança — apresentou-se com boa-fé diante do Poder Público, confiou que seria amparado, no momento em que mereceria descanso remunerado pelos anos de trabalho e contribuição árduos.

No âmbito da Administração Pública, braço executor da função administrativa do Estado, dar segurança jurídica ao cidadão, ao servidor público, é tão somente exercer da forma mais correta os vetores emanados do Estado Democrático de Direito.

Do Poder Público exige-se comportamento previsível e comprometido com aqueles que nele depositam boa-fé. Previsível de acordo com os ideais de justiça, ao que se denomina, em nosso entendimento, um dos vieses da juridicidade; comprometido, em fazer com que os comandos determinados pela norma jurídica produzam efeitos concretos correspondentes à expectativa da "sociedade política estatal". ${ }^{14}$

Quando se rompe a segurança positivada e se adere ao estado de instabilidade das relações jurídicas, temos presente a traição aos preceitos constitucionais, mais ainda, àqueles preceitos que justificam a formação do Estado como instituição. Ao desconsiderar a previsão implícita da segurança jurídica, desestabilizando a vida do cidadão, desrespeita-se a boa-fé daqueles que cumpriram sua parte diante do acordado, gerando, então, descrédito nas relações onde ele é parte signatária.

\section{A dignidade da pessoa humana e a segurança jurídica}

Entende-se caber a exaltação do princípio da dignidade da pessoa humana, por ser vetor revelado explicitamente pela Constituição, já no primeiro momento, informando qual caminho seguirá a atuação do Poder Público Estatal.

A dignidade pode ser observada sobre o prisma de um complexo de direitos e deveres fundamentais que assegurem à pessoa, tanto contra todo e qualquer ato de cunho degradante e desumano, como venham a lhe garantir as condições mínimas para uma vida saudável. ${ }^{15}$

Lembra-se então, que para que se respeite plenamente a dignidade da pessoa humana, é preciso considerar aquilo que lhe dará amparo para o exercício de uma cidadania plena. A segurança, portanto, é fundamento dessa dignidade, já que não se pode conceber, nos dias de hoje, o indivíduo mantido sob regime, mesmo legitimado pelo Direito, de insegurança,

\footnotetext{
14 Neste sentido,demonstra-se inexistir qualquer supremacia da atividade legislativa sobre a atividade administrativa. Ambas são fenômenos do mesmo fazer do Estado:o fazer o Direito para a concretização da ideologia jurídica acreditada pela sociedade política estatal. ROCHA, 1994, p. 84.

${ }^{15}$ Conceito proposto por SARLET, 2004.
}

A \& C R. de Dir. Administrativo e Constitucional, Belo Horizonte, ano 6, n. 25, p. 133-144, jul./set. 2006 
incerteza, intranqüilidade, compatibilizado com o ideal de justiça.

Para legitimar a atuação estatal, é necessário que o cidadão se sinta confiante, parte, e não mero instrumento da vontade dos governantes. Se os direitos fundamentais constituem-se em personificações dessa dignidade, a segurança garantida, no mesmo rol constitucional, pela previsão de respeito ao ato jurídico perfeito, ao direito adquirido e à coisa julgada, ao ser desrespeitada, automaticamente desconsiderará o princípio exaltado no artigo $1^{\circ}$ da Constituição Federal de 1998.

Parece evidente, portanto, que só é possível ao Estado, respeitar a dignidade da pessoa humana, amplamente ressaltada na Constituição, se observar a proteção da confiança do cidadão na ordem jurídica vigente. Ao proteger a confiança, protege-se a boa-fé do cidadão perante o Poder Público.

O princípio da boa-fé, característico da pessoa humana, e exaltado universalmente pela melhor doutrina, traduz a confiabilidade depositada nos governantes para gerir a coisa pública sempre em prol do interesse público. Abarca a obrigação do Estado em implantar e implementar todos os direitos, em mantê-los à salvo de reveses de humor, em garantir estabilidade na relações jurídicas e sociais.

\section{Conclusão}

É fato que vive-se um momento histórico de incertezas e inseguranças, marcados pela transitoriedade das relações intersubjetivas, pelo desrespeito à dignidade e à vida humana. Tal crise gera para o homem a urgente necessidade de estabilizar as relações sociais e jurídicas, aliviar as angústias e incertezas através de um sistema normativo mais coerente, função fundamental e imediata do Direito.

O cunho jurídico da segurança tem se manifestado particularmente nas relações entre o Estado e o indivíduo, traduzindo-se, inicialmente, na exigência de adequação de toda e qualquer atividade estatal aos valores de justiça, moral e igualdade, pois a concepção social do Estado de Direito não se satisfaz com a mera existência de um Direito legalista e formal, a garantir coativamente o cumprimento de previsões desprovidas de finalidade pública.

Ao se compreender o princípio da segurança jurídica como garantia de disposição e formulação regular das normas e instituições integrantes de um sistema jurídico; como regra de cumprimento do direito por todos 
os seus destinatários com a devida atuação dos órgãos encarregados de sua aplicação, protegendo, portanto, o sentimento de confiança do cidadão para com o Estado, alcançamos o entendimento de que a segurança jurídica representa direito garantido substancialmente pelo Estado Democrático de Direito.

A Administração Pública, em sua função administrativa, ${ }^{16}$ tem como obrigação observar e preservar tal princípio já que lhe é determinado fazer, de acordo com a lei, tudo aquilo que atenda às necessidades de interesse público da forma mais eficiente. O cuidado com a lisura nas relações jurídicas, não vincula tão somente aquelas travadas com o cidadão, destinatário final da atividade, mas tanto quanto com as relações mantidas com o servidor público, agente que empresta sua mobilidade ao Estado, para que se concretize tudo o que prevê o ordenamento.

Ao agente, também caberá agir em conformidade com os vetores determinados pelos princípios constitucionais implícitos e explícitos, ascendentes daqueles que compõem os regimes jurídicos dos vários institutos existentes no Direito. Isso implica em dizer que a ação política que define os vetores para atividade administrativa não se furtam à mesma obediência, tendo em vista a origem de seu poder: a legitimação dele através da democracia representativa.

A dignidade humana deve ser a pauta principal das ações governamentais e administrativas, permitindo que a segurança, tão arduamente desejada possa ser sentida e exercida. A segurança jurídica é a positivação da necessidade de proteção do cidadão contra aquele que se apresenta com maior poder de interferência na ordem dos direitos individuais, buscando equilibrar a coexistência dos direitos, públicos e privados.

Ressalta-se, porém, que, embora a jurisprudência e doutrina pátrias entendam não haver discussão sobre direito adquirido diante de regime jurídico, a opinião de Luís Roberto Barroso ${ }^{17}$ está presente na construção desse estudo, que insiste em dizer ser impossível impedir a aquisição de direitos a partir de relações jurídicas legitimamente e legalmente travadas, pois a possibilidade legal de alteração das condições pré-estabelecidas, não afasta a proteção constitucional ao direito. Se assim fosse, não precisaríamos constituir normas de nenhuma ordem. Quando se nega a possibilidade do direito adquirido diante de regimes jurídicos especiais,

\footnotetext{
${ }_{16}$ MELLO, 2006.
}

17 BARROSO, 2004

A \& C R. de Dir. Administrativo e Constitucional, Belo Horizonte, ano 6, n. 25, p. 133-144, jul./set. 2006 
pautando-se na supremacia do interesse público, nega-se o próprio interesse público, nega-se a legalidade protetora desse interesse, pois a razão de ser da lei — a segurança — foi negada. O fim estimado para a existência de um ordenamento magno é tão somente garantir a realização de certos fins considerados pelo homem como indispensáveis à sua existência e convivência harmônica em sociedade. O que nos remete imediatamente à necessidade de segurança social positivada.

Resta reconhecer que Direito e Segurança caminham juntos, sendo esta uma qualidade do Estado Democrático de Direito. É preciso, pois, possibilitar aos cidadãos, destinatários do direito, seu conhecimento, assegurando a certeza de que a legalidade não será manipulada a ponto de coibir o exercício digno da cidadania, dos direitos conquistados pelo homem e que se fundam na própria existência do ser humano, dentre eles o direito de sentir-se minimamente protegido.

Como busca incessante do homem, direito nascido com o Estado e constituído com a Constituição, sustenta-se que a segurança não poderá ser desrespeitada e desconsiderada no âmbito de nenhuma relação jurídica travada entre indivíduo-indivíduo ou entre Estado-indivíduo.

\section{Referências}

BARROSO, Luis Roberto. Em algum lugar do passado: segurança Jurídica, direito intertemporal e o novo Código Civil. In: ROCHA, Cármen Lúcia Antunes (Org.). Constituição e segurança jurídica: direito adquirido, ato jurídico perfeito e coisa julgada. Estudos em homenagem a José Paulo Sepúlveda Pertence. Belo Horizonte: Fórum, 2004.

BOBBIO, Norberto. Teoria geral da política. Rio de Janeiro: Campus, 2000.

CANOTILHO, José Joaquim Gomes. Direito constitucional e teoria da Constituição. 4. ed. Coimbra: Almedina, 2001.

DALLARI, Dalmo de Abreu. Elementos da teoria geral do Estado. 21. ed. atual. São Paulo: Saraiva, 2000.

FONSECA, Ricardo Marcelo (Org.). Repensando a teoria do Estado. Belo Horizonte: Fórum, 2004.

ENGELS, Friedrich. A origem da família, da propriedade privada e do estado.

GARCIA NOVOA, César. Seguridad jurídica y derecho tributário. In: ROCHA, Cármen Lúcia Antunes (Org.). Constituição e segurança jurídica: direito adquirido, ato jurídico perfeito e coisa julgada. Estudos em homenagem a José Paulo Sepúlveda Pertence. Belo Horizonte: Fórum, 2004.

HOBBES, Thomas. Leviatã ou Matéria, forma e poder de um Estado eclesiástico e civil. São Paulo: Nova Cultural, 1997. (Os Pensadores).

A \& C R. de Dir. Administrativo e Constitucional, Belo Horizonte, ano 6, n. 25, p. 133-144, jul./set. 2006 
KELSEN, Hans. Teoria geral do direito e do Estado. Tradução de Luís Carlos Borges. 3. ed. São Paulo: Martins Fontes, 1998.

MELLO, Celso Antonio Bandeira de. Curso de direito administrativo. 20. ed. rev e atual. São Paulo: Malheiros, 2006.

OLIVEIRA, Odília Ferreira da Luz. Manual de direito administrativo. Rio de Janeiro: Renovar, 1997.

ROCHA, Cármen Lúcia Antunes (Org.). Constituição e segurança jurídica: direito adquirido, ato jurídico perfeito e coisa julgada. Estudos em homenagem a José Paulo Sepúlveda Pertence. Belo Horizonte: Fórum, 2004a.

ROCHA, Cármen Lúcia Antunes. Princípios constitucionais da Administração Pública. Belo Horizonte: Del Rey, 1994.

ROCHA, Cármen Lúcia Antunes. O princípio da coisa julgada e o vício de inconstitucionalidade. In: ROCHA, Cármen Lúcia Antunes (Org.). Constituição e segurança jurídica: direito adquirido, ato jurídico perfeito e coisa julgada. Estudos em homenagem a José Paulo Sepúlveda Pertence. Belo Horizonte: Fórum, 2004b.

SARLET, Ingo Wolfgang. A eficácia do direito fundamental à segurança jurídica: dignidade da pessoa humana, direitos fundamentais e proibição de retrocesso social no direito constitucional brasileiro. In: ROCHA, Cármen Lúcia Antunes (Org.). Constituição e segurança jurídica: direito adquirido, ato jurídico perfeito e coisa julgada. Estudos em homenagem a José Paulo Sepúlveda Pertence. Belo Horizonte: Fórum, 2004.

SARLET, Ingo Wolfgang. A eficácia dos direitos fundamentais. 3 ed. rev. atual e ampl. Porto Alegre: Liv. do Advogado, 2003.

Informação bibliográfica deste texto, conforme a NBR 6023:2002 da Associação Brasileira de Normas Técnicas (ABNT):

MELO, Lígia Maria Silva de. Segurança jurídica: fundamento do Estado de Direito. A\&C Revista de Direito Administrativo e Constitucional, Belo Horizonte, ano 6, n. 25, p. 133-144, jul./set. 2006. 